\title{
Al servicio del Rey: \\ la oficialidad aristocrática de "nación" italiana en los ejércitos borbónicos (1700-1808)
}

\author{
Davide MAFFI \\ Ricercatore \\ Università degli Studi di Pavia \\ Dipartimento di Scienze Storiche e Geografiche "Carlo M. Cipolla" \\ Ex convento San Tommaso \\ P.zza del Lino, 2 \\ I-27100 Pavía, Italia \\ davide.maffi@unipv.it
}

Fecha de recepción: 01/09/2011

Fecha de aceptación: 15/12/2011

\section{RESUMEN}

La historia de la presencia de la aristocracia italiana en los ejércitos españoles del siglo XVIII es una historia olvidada. El presente trabajo analiza esta persistencia de la nobleza italiana en los ejércitos de los Borbones, su proveniencia y las causas, políticas y sociales, de la conservación y duración de esta relación especial entre las grandes casas nobiliarias de gran parte de la península italiana y la corte de Madrid.

Palabras clave: ejército, Borbones, Italia, aristocracia italiana, militares italianos.

\section{At the King's Service:}

\section{The Italian aristocratic officers in the Spanish Bourbon Army (1700-1808)}

\begin{abstract}
The history of the presence of the Italian aristocracy in the Eighteenth Century Spanish army is a neglected history. This work analyzes the persistence of Italy's great noble families in the Spanish Bourbon armies, their origin and the political and social causes of the duration of a special relationship between the Italian noble houses and the court of Madrid.
\end{abstract}

Key words: Army, Bourbon Spain, Italy, Italian aristocracy, Italian military men.

La historia de una relación olvidada. Así, en pocas palabras, se puede resumir el trayecto de la nación italiana en la España del siglo XVIII y en particular de la oficialidad aristocrática de origen peninsular que prestó servicio en los ejércitos de los Borbones. La historiografía italiana prácticamente ha dejado pasar bajo silencio, casi hasta nuestros días, la persistencia de unos fuertes vínculos clientelares que siguieron existiendo entre Madrid y las varias regiones italianas a lo largo del siglo 
XVIII, limitándolos, en la mejor de las hipótesis, a los reinos meridionales, donde a partir de 1734 se instaló una rama de los Borbones ${ }^{1}$. Se ha olvidado, sin embargo, casi por entero -salvo algunas notables excepciones ${ }^{2}-$, como también en el norte y el centro persistieron todavía fuertes enlaces entre las élites locales y Madrid, que no se interrumpieron tras el final de la preeminencia española después de la guerra de Sucesión española.

Tampoco ha tenido mucha mejor suerte en Italia la historia militar, y en particular la del siglo XVIII ${ }^{3}$. Generalmente considerada como una época de mera decadencia de las virtudes militares "nacionales" - con la notable excepción del Piamonte, donde se constituyó un verdadero estado militar al estilo prusiano ${ }^{4}$, esta época ha sido totalmente ignorada por los historiadores ${ }^{5}$, que supinamente han aceptado la idea de

\footnotetext{
1 Recordemos sólo como un clásico manual sobre la historia italiana del XVIII como el de CARPANETTO, Dino y Ricuperati, Giuseppe: L'Italia del Settecento. Crisi Trasformazioni Lumi, Roma y Bari, Editori Laterza, 1986, pasa bajo silencio las fuertes vinculaciones que todavía siguieron existiendo entre las élites italianas del centro y norte del país y la corte de Madrid. El trabajo más completo dedicado a la Italia de las Luces, los cinco volúmenes de Franco Venturi de Settecento Riformatore publicados entre 1969 y 1990 (Da Muratori a Beccaria (1730-1764), Turín, Einaudi, 1969; La Chiesa e la Repubblica dentro i loro limiti (1758-1774), Turín, Einaudi, 1976; La prima crisi dell'Antico Regime (1768-1779), Turín, Einaudi, 1979; La caduta dell'Antico Regime (1776-1789), tomo I, I grandi stati dell'Occidente, Turín, Einaudi, 1984; La caduta dell'Antico Regime (1776-1789), tomo II, Il patriottismo repubblicano e gli imperi dell'Est, Turín, Einaudi, 1984; L'Italia dei lumi, tomo I, La rivoluzione di Corsica, le grandi carestie degli anni Sessanta, la Lombardia delle riforme (1764-1790), Turín, Einaudi, 1987; L'Italia dei lumi, tomo II, La Repubblica di Venezia (1761-1797), Turín, Einaudi, 1990), llena de preciosas informaciones sobre las fuertes vinculaciones entre los reinos meridionales y España, se olvida prácticamente por entero de la situación en el norte del país. También obras más recientes casi han ignorado la situación referente al siglo XVIII, por ejemplo Martínez Millán, J. y Rivero Rodríguez, M. (coords.): Centros de poder italianos en la Monarquía (siglos XVIXVIII), 3 vols., Madrid, Editorial Polifemo, 2010, no tiene casi ninguna referencia relativa a las persistencias de los enlaces políticos y militares entre los dos países. Unas liasons que son mejor investigadas en FraGNITo, Gigliola (ed.): Elisabetta Farnese principessa di Parma e regina di Spagna, Roma, Viella, 2009.

2 Véase por ejemplo las páginas que Andrea Merlotti dedica a aquella nobleza del Piamonte oriental, territorio español hasta 1713, que todavía a la mitad del siglo XVIII miraba más hacia Madrid y hacia Viena que hacia la propia Turín: Merlotti, Andrea: L'enigma delle nobiltà. Stato e ceti dirigenti nel Piemonte del Settecento, Florencia, Leo C. Olschki, 2000
}

3 Sobre el desinterés por parte de la historiografía italiana después de la Segunda Guerra mundial por los temas vinculados con la historia militar remito a las consideraciones expuestas en las páginas de Del Negro, Piero: «La storia militare dell'Italia moderna nello specchio della storiografia del Novecento», Cheiron, 23 (1995), pp. 11-33; DonATI, Claudio: «Il "militare" nella storia dell'Italia moderna dal Rinascimento all'età napoleonica», en DoNATI, Claudio (ed.): Eserciti e carriere militari nell'Italia moderna, Milán, UNICOPLI, 1998, pp. 7-39. Una reciente visión sobre la cuestión de la historiografía militar de la Edad Moderna en AnTonielli, Livio e DonAti, Claudio (eds.): Al di là della storia militare: una ricognizione sulle fonti, Soveria Mannelli (CZ), Rubbettino, 2004.

4 Una situación que dio lugar a una "leyenda áurea", en buena parte bien merecida, sobre las virtudes militares del pequeño estado italiano nacida en los años del Risorgimento y ampliada en las décadas siguientes a la formación del estado nacional italiano por los hagiógrafos de los Saboya y entre las dos guerras por el régimen fascista. El caso piamontés sigue siendo uno de los más investigados por parte de la historiografía, no sólo italiana. Aquí recordaremos los recientes trabajos de BARBeris, Walter: Le armi del principe. La tradizione militare sabauda, Turín, Einaudi, 1988; Loriga, Sabina: Soldati. L'istituzione militare nel Piemonte del Settecento, Venecia, Marsilio, 1992; BIANCHI, Paola: Onore e mestiere. Le riforme militari nel Piemonte del Settecento, Turín, Silvio Zamorani Editore, 2002; Storrs, Christopher: War, Diplomacy and the Rise of Savoy, 1690-1720, Cambridge, Cambridge University Press, 1999. Una síntesis reciente sobre la cuestión en BiAnCHI, Paola: «Dal mestiere delle armi alla carriera militare. Il caso sabaudo tra XVII e XVIII secolo», en DONATI, C. y KROENER, B. (eds.): Militari e società civile nell'Europa dell'età moderna (secoli XVI-XVIII), Bolonia, Il Mulino, 2007, pp. 351-399.

5 Quitando los trabajos dedicados a Piamonte, pocas son de hecho las obras dedicadas a la historia militar italiana en la época de la Ilustración. Aquí recordaremos simplemente, además de los trabajos citados en las notas anteriores y posteriores, las páginas de RAO, Anna Maria: «Esercito e società a Napoli nelle riforme del secondo Settecento», en DonATI: op. cit. (nota 3, 1998), pp. 147-214. Una reseña se puede encontrar en DonATI, Claudio: «Strutture militari 
una desmilitarización de las élites peninsulares iniciada desde fines del siglo XVI y que llegó a su cúlmen dos siglos más tarde ${ }^{6}$.

En realidad siguió permaneciendo una fuerte vinculación entre muchas de las grandes familias nobiliarias del país y el servicio militar todavía bien entrado el siglo XVIII, algo que la historiografía nacional ha pasado casi enteramente bajo silencio ${ }^{7}$. Los italianos siguieron siendo, por ejemplo, un componente fundamental en el ejército de los Austrias vieneses, donde continuaron sus servicios unos cuantos oficiales de origen italiano que no provenían sólo de regiones como el Ducado de Milán, puestas directamente bajo la administración imperial, sino también de otros estados peninsulares ${ }^{8}$. Los oficiales italianos siguieron prestando no sólo sus servicios en Francia ${ }^{9}$, sino también en varios de los pequeños estados alemanes ${ }^{10}$.

No menos importante pareció su presencia en los ejércitos borbónicos españoles a lo largo de todo el siglo XVIII, cuando varias unidades de naciones entraron a formar parte de la tropa empeñada en las guerras europeas y coloniales y entre ellos varios regimientos de italianos ${ }^{11}$. Ya en 1715 Felipe $\mathrm{V}$ decidió mantener en pie los

degli Stati italiani nella prima età moderna: una rassegna degli studi recenti», en La storiografia militare in Francia e in Italia negli ultimi vent 'anni. Due esperienze a confronto, cuaderno de la Società Italiana di Storia Militare, año 2000 (en realidad 2003), pp. 45-62.

6 La visión ligada a la pérdida de las "virtudes guerreras" por parte de las aristocracias peninsulares es un tópico que tuvo una gran difusión a partir de la primera mitad del siglo XIX cuando, al cúlmen del proceso risorgimentale, se culpó a la escasa vocación marcial de gran parte de los antiguos estados italianos como una de las causas que llevaron al país a caer bajo dominación extranjera. Un mito ampliado en los decenios siguientes a la unificación nacional (como se puede ver todavía en las páginas de PIERI, Piero: Il Rinascimento e la crisi militare italiana, Turín, Einaudi, 1952) y que ha llegado casi intacto hasta nuestros días. Sobre todo esto remito al trabajo de Hanlon, Gregory, The twilight of a military tradition. Italian aristocrats and European conflicts, 1560-1800, Londres, University College London Press, 1998.

7 Una notable excepción en este panorama son los trabajos de DonATI, Claudio: «Esercito e società civile nella Lombardia del secolo XVIII: dagli inizi della dominazione austriaca alla metà degli anni Sessanta», Società e Storia, XVII (1982), pp. 527-554; y «L'organizzazione militare della monarchia austriaca nel secolo XVIII e i suoi rapporti con i territori e le popolazioni italiane. Prime ricerche», en Mazohl-Wallnig, B. y Meriggi, M. (eds.): Österreichisches Italien-Italienisches Österreich? Interkulturelle Gemeinsamkeiten und nationale Differenzen vom 18. Jahrundert bis zum Ende des Ersten Weltkrieges, Viena, Verlag der Osterreichischen Akademie der Wissenschaften, 1999, pp. 297-329, que ha subrayado la perpetuación de una vocación militar en la aristocracia milanesa a lo largo del siglo XVIII. Los fuertes vínculos entre los aristócratas y la profesión de las armas siguieron todavía existiendo en el reino de Nápoles y de Sicilia, con la oficialidad borbónica casi totalmente proveniente de las familias más prestigiosas del país: KNIGHT, Carlo: «Le forze armate napoletane durante la minorità di Ferdinando IV di Borbone. Organico, soldo e sistema pensionistico», Archivio Storico per le Province Napoletane, CXI (1993), pp. 329-362.

8 Como olvidar el caso del piamontés Pietro Guasco, teniente general de la Kaiserliche Armee, heroico defensor de la plaza de Schweidnitz durante la guerra de los Siete Años: Duffy, Christopher: The Fortress in the Age of Vauban and Frederick the Great, 1660-1789, Londres, Routledge \& Kegan Paul, 1985, pp. 126, 128. En general, la oficialidad italiana gozó de una gran reputación en el ejército imperial durante todo el siglo XVIII: DufFy, Christopher: The army of Maria Theresa. The Armed Forces of Imperial Austria, 1740-1780, Londres y Vancouver, David \& Charles, 1977 , p. 26. Sobre las fuerzas armadas de Viena remito también al reciente trabajo de HochedLinger, Michael: Austria's Wars of Emergence 1683-1797, Londres, Longman, 2003.

9 Donde siguieron conservando dos regimientos de infantería, algunas unidades de caballería, además de un cierto número de oficiales repartidos en otras unidades: Duffy, Christopher: The Military Experience in the Age of Reason, Londres, Routledge \& Kegan Paul, 1987, p. 33.

10 Como en el ejército bavarés: Reduich, Fritz: The German Military Enterprise and his work force. A Study in European Economic and Social History, 2 vols., Wiesbaden, Franz Steiner Verlag GMBH, 1964-65, vol. II, p. 129.

11 Como en los siglos precedentes, en los varios ejércitos europeos siguieron prestando sus servicios varias unidades de mercenarios de varia proveniencia. El mejor estudio sobre el mundo militar de este siglo sigue siendo el trabajo de DufFY: op. cit. (nota 9). Sobre el arte de la guerra y las campañas militares, una buena visión de conjunto se encuentra en las páginas de BLACK, Jeremy: European Warfare 1660-1815, Londres, University College London 
regimientos de Nápoles, Milán, Parma, Cerdeña y Sicilia. En los años siguientes las campañas militares llevadas a cabo para recuperar parte de los territorios italianos vieron una nueva inyección de tropas peninsulares con la leva, entre 1717 y 1718, de los regimientos de infantería de Augusta, Italia, Liguria, Valdemazzara, Valledomini, Valdenoto, Messina, Palermo, Toscana. Tras la desmovilización de 1721 se conservaron todavía en servicio nueve batallones de italianos, muchos de los cuales tomaron parte en las siguientes guerras de Sucesiones polaca y austriaca, en las campañas de Italia contra los austriacos. El fin de la política italiana de Felipe V y el cambio radical impuesto por parte de Fernando VI a partir de 1746, más de contención internacional que de imposición ${ }^{12}$, vio una profunda reorganización del ejército con la reforma de gran parte de las unidades italianas: a partir de 1749 los cuerpos italianos se quedaron reducidos a solo dos regimientos de infantería (el de Milán y el de Nápoles), con cuatro batallones, y a dos regimientos de caballería (el de Milán y los dragones de Pavía), que se quedaron en servicio hasta finales del siglo ${ }^{13}$.

Seguramente menos investigados con respecto a los irlandeses ${ }^{14}$, a los flamencos ${ }^{15}$, o a otras naciones en servicio en los reales ejércitos, los oficiales de origen italiano en el XVIII representaron el porcentaje más elevado entre los extranjeros, con un $2,77 \%$ del total contra el $1,72 \%$ de los flamencos, el $1,05 \%$ de franceses, el $0,32 \%$ de portugueses, el $0,22 \%$ de los irlandeses, el $0,12 \%$ de los alemanes y sólo el $0,02 \%$ de suizos ${ }^{16}$. Un servicio que no se limitaba sólo a los regimientos de origen italiano, dado que la oficialidad de esta nación fue repartida en varias unidades de naciones como los regimientos flamencos (el de Bruselas y de Brabante, como también en la Real Guardia valona), suizos (el de Elvetia) e irlandeses (como el de Ultonia); o de peninsulares (como los de caballería de Montesa, de las Órdenes, de Algarve, o de infantería como el regimiento de Cataluña).

Press, 1994. Además de unidades de origen italiana, los Borbones aprovecharon también los servicios de irlandeses, flamencos, alemanes, suizos. Sobre el ejército español del siglo XVIII véase GómEz RuIz, Manuel y Alonso JuAnOLA, Vicente: El ejército de los Borbones. Organización, uniformidad, divisas y armamento, 8 vols., Madrid, Servicio Histórico Militar, 1989-2009, en particular los volúmenes 1 y 2, que abarcan los reinados de Felipe V, Fernando VI y Carlos III.

12 Sobre la política exterior de estos dos reinados, y en particular a la política italiana de Felipe V, reenvio a las recientes consideraciones de RuIZ Torres, Pedro: Reformismo e Ilustración, Barcelona, Crítica-Marcial Pons, 2008, pp. 184-202.

13 Sobre estas unidades remito a las páginas de AndúJar CAStillo, Francisco: «Entre la corte y la guerra. Militares italianos al servicio de España en el siglo XVIII»; y de MARChENA FERnÁndeZ, Juan: «Italianos al servicio del rey de España en el ejército de América. 1740-1815», ambos en BIANCHI, P. y otros (eds.): Italiani al servizio straniero in età moderna, Milán, FrancoAngeli, 2008, respectivamente en pp. 105-134 y 135-175.

14 Véase los ensayos recogidos en García Hernán, Enrique y Recio Morales, Óscar (coords.): Extranjeros en el ejército. Militares irlandeses en la sociedad española, 1580-1818, Madrid, Ministerio de Defensa, 2007; y la reciente aportación de síntesis de Recio Morales, Óscar: Ireland and the Spanish Empire 1600-1825, Dublín, Four Courts Press, 2010, con su abundante bibliografía.

15 Glesener, Thomas: «Le frontières de la nation. L'identité corporative d'un régiment étranger dans l'armée espagnole (XVIII ${ }^{\mathrm{e}}$ siècle)», en Bertrand, M. y Planas, N. (eds.): Les sociétés de frontière. De la Méditerranée à l'Atlantique (XVI -XVIII siècle), Madrid, Casa de Velázquez, 2011, pp. 243-257; y, del mismo, «¿Nación flamenca o elite de poder? Los militares "flamencos" en la España de los Borbones», en GARCía GARCÍA, B.J. y Álvarez-Ossorio Alvariño, A. (eds.): La Monarquía de las naciones. Patria, nación y naturaleza en la Monarquía de España, Madrid, Fundación Carlos de Amberes, 2004, pp. 701-719.

16 Andúuar Castillo, Francisco: Los militares en la España del siglo XVIII. Un estudio social, Granada, Servicio de Publicaciones de la Universidad de Granada, 1991, p. 315. 
Sin embargo, no obstante la constante presencia de esta oficialidad y su importancia no sólo para el ejército sino también para la historia de la armada española ${ }^{17}$, ésta, como ya hemos apuntado en las páginas anteriores, ha sido objeto de escasa investigación no sólo por parte italiana, sino también por parte de la historiografía española ${ }^{18}$. El presente ensayo no quiere seguramente abarcar por entero la historia de los oficiales que sirvieron en los ejércitos reales, sino, partiendo del análisis de los estados de servicios de algunos centeneras de personajes (poco más de trescientos), averiguar la proveniencia, su origen social, la carrera y las estrategias familiares de este grupo social ${ }^{19}$.

El porcentaje más alto de la oficialidad italiana en servicio siguió procediendo de los territorios del sur del país, Nápoles y Sicilia (véase cuadro I), que mantuvieron fuertes enlaces con la corte de Madrid gracias, por un lado, a la "recuperación" de estos dos reinos por parte de Felipe V al final de la guerra de Sucesión polaca ${ }^{20}$, y por otro, a la instauración de una rama de los Borbones en el trono de los dos dichos estados peninsulares ${ }^{21}$. Una relación privilegiada que siguió siendo muy fuerte también en los decenios de gobierno imperial (1707-1734), cuando la nobleza napolitana seguía mirando más hacia Madrid que hacia Viena en la búsqueda de empleos, mercedes y gratificaciones para sus cadetes ${ }^{22}$. Son años estos en los cuales varios exponentes de las élites napolitanas siguieron ingresando en las fuerzas armadas españolas. Entre ellos destacamos a Rodolfo Acquaviva, cadete de la guardia de corps, coronel del regimiento de caballería de Barcelona en 1718, brigadier en $1728^{23}$. Los Caracciolo, representados por el brigadier Carlo Maria, veterano de las guerras de los Austrias (ingresó en 1695), coronel en 1704 y que se mantuvo al servicio de Felipe V hasta

17 Parece oportuno subrayar que el almirante en jefe de la armada española en la jornada de Trafalgar, Federico Gravina, era siciliano de origen, mientras que uno de los más grandes marinos y exploradores recordados en España, el marqués Alessandro Malaspina, era toscano: O’Donnell, Hugo: La campaña de Trafalgar. Tres naciones en pugna por el dominio del mar (1805), Madrid, La Esfera de los Libros, 2005; GALERA GómEz, Andrés: Las corbetas del rey. El viaje alrededor del mundo de Alejandro Malaspina (1789-1794), Bilbao, Fundación BBVA, 2010.

18 Con la notable excepción de los artículos citados en la nota 13.

19 En los casos analizados no se ha tenido en cuenta el grado de sargento, que en el siglo XVIII seguía siendo considerado el rango más bajo del escalafón de la oficialidad y donde casi siempre se quedaban sirviendo los profesionales de la guerra de origen humilde.

20 Entre las guerras europeas del siglo XVIII esta es seguramente la que ha tenido menor consideración por parte de la historiografía moderna. Un desdén sobre el cual ha pesado la neutralidad de Inglaterra, que ha llevado a los historiadores anglosajones, que son quienes más se han dedicado a la histoire bataille de este siglo, a borrarla casi completamente del plano. Un útil compendio para la situación italiana se puede encontrar en GaLAsso, Giuseppe: «L'Italia una e diversa nel sistema degli stati europei (1450-1750)», en Galasso, Giuseppe y Mascilli MiglioRINI, Luigi: L'Italia moderna e l'unitá nazionale, Turín, UTET, 1998, pp. 369-387. La actuación de las tropas españolas en la Península italiana está resumida en Borreguero Beltrán, Cristina: «Los soldados españoles en Italia (1734)», en El Mediterráneo: hechos de relevancia histórico-militar y sus repercusiones en España, Sevilla, Cátedra "General Castaños"-Región Militar Sur, 1997, pp. 700 y ss.

${ }_{21}$ Sobre el Nápoles borbónico remito a las páginas de GaLAsso, Giuseppe: Il Mezzogiorno borbonico e napoleonico, 1734-1815, Turín, UTET, 2007. Sobre Sicilia a GIARrizzo, Giuseppe: «La Sicilia dal Cinquecento all'Unità d'Italia», en Giarrizzo, Giuseppe y D'Alessandro, Vincenzo: La Sicilia dal Vespro all'Unità d'Italia, Turín, UTET, 1989, pp. 377-544.

22 Spagnoletti, Angelantonio: «Famiglie aristocratiche meridionali tra Spagna e Austria nei primi decenni del Settecento», en Russo, S. y GuAsti, N. (eds.): Il Viceregno austriaco (1707-1734). Tra capitale e province, Roma, Carocci, 2010, pp. 64-76. Sobre la breve historia del Nápoles austriaco véase también GaLAsso, Giuseppe: Il Regno di Napoli. Il Mezzogiorno spagnolo e austriaco (1622-1734), Turín, UTET, 2006, pp. 821-1033.

${ }_{23}$ Archivo General de Simancas (en adelante AGS), Secretaría de Guerra (SG), leg. 2471, carpeta (c.) VIII, f. 2. 
llegar a ser comandante del regimiento de infantería de Toledo ${ }^{24}$; o Giovanni Battista, voluntario en los reales ejércitos en 1707, capitán en 1709, sargento mayor en 1714 $\mathrm{y}$, finalmente, teniente corone $^{25}$. O, para finalizar, el mariscal de campo Giuseppe Dattolo, cadete en el regimiento de Montesa en 1728, coronel de artillería en 1760 (después de haber ascendido todo el escalafón en dicha arma), brigadier y mariscal de campo en $1779^{26}$.

\section{Cuadro I. Área geográfica de proveniencia de los oficiales italianos en el ejército borbónico del XVIII}

\begin{tabular}{|c|c|}
\hline \multicolumn{2}{|l|}{ Proveniencia } \\
\hline \multicolumn{2}{|l|}{ Reino de Cerdeña: } \\
\hline Piamonte & $35(11,44 \%)$ \\
\hline Cerdeña & $5(1,63 \%)$ \\
\hline Total & $40(13.07 \%)$ \\
\hline Estado de Milán & $56(18,30 \%)$ \\
\hline República de Venecia & $17(5,56 \%)$ \\
\hline República de Génova & $27(8,82 \%)$ \\
\hline Ducado de Parma y Plasencia & $14(4,58 \%)$ \\
\hline Ducado de Módena y Reggio & $4(1,30 \%)$ \\
\hline República de Lucca & $5(1.63 \%)$ \\
\hline Gran Ducado de Toscana & $40(13.07 \%)$ \\
\hline Estado de la Iglesia & $22(7,19 \%)$ \\
\hline \multicolumn{2}{|l|}{ Reinos de Nápoles y Sicilia: } \\
\hline Nápoles & \\
\hline Sicilia & \\
\hline Total & $81(26,48 \%)$ \\
\hline TOTAL GENERAL & 306 \\
\hline
\end{tabular}

Fuentes: AGS SG leg. 407 fs. 161, 163, 209, 215, 256, 323, 617, 635; leg. 408 fs. 68, 223, 393; leg. 409 fs. 20, 48, 113, 181, 231; leg. 410 fs. 5, 7, 12, 28; leg. 411 fs. 125, 150, 196, 214; leg. 2462 c. II f. 12, c. XII f. 17; leg. 2464 c. II f. 33, c. III f. 6, c. VII f. 115 ; leg. 2465 c. II f. 6, c. IV f. 4, c. V f. 5; leg. 2466 c. I f. 12, c. III f. 10; leg. 2467 c. II f. 3; leg. 2468 c. XIII fs. 5, 14; leg. 2469 c. II f. 13, c. V f. 2; leg. 2470 c. I f. 36; leg. 2471 c. VIII f. 2, c. XII f. 34, c. XVIII f. 6; leg. 2472 c. XII f. 8, c. XIII f. 7, c. XXI fs. 135, 136; leg. 2474 c. VIII fs. 21, 46; leg. 2475 c. II fs. 1, 36, c. III f. 23; leg. 2476 c. XIV f. 8; leg. 2477 c. X fs. 1, 22; leg. 2478 c. I f. 18, c. II f. 1; leg. 2479 c. I f. 4; leg.

\footnotetext{
24 AGS, SG, leg. 2664, c. XVIII, f. 40.

25 AGS, SG, leg. 2636, c. X, f. 38.

26 AGS, SG, leg. 410, f. 12.
} 
2480 c. I f. 1, c. III f. 7; leg. 2482 c. VII f. 1; leg. 2483 c. II fs. 30, 40; leg. 2484 c. VIII f. 1, c. IX f. 75; leg. 2485 c. IX f. 5; leg. 2489 c. III f. 15, c. IV f. 53, c. VIII f. 5, c. IX f. 17 , c. XI fs. 11, 14; leg. 2492 c. II f. 11, c. VII f. 17, c. X f. 25, c. XII f. 2, c. XIII f. 22; leg. 2493 c. VI f. 23, c. VII f. 27; leg. 2494 c. IV f. 3; leg. 2495 c. II f. 9, c. VI f. 39; leg. 2503 c. II fs. 1, 11; leg. 2504 c. III f. 7, c. XVII f. 40; leg. 2509 c. V f. 141, c. VIII fs. 21, 36; leg. 2515 c. VI f. 6; leg. 2521 c. II f. 69; leg. 2522 c. V f. 3, c. XI fs. 3, 27; leg. 2527 c. VII f. 13; leg. 2531 c. V f. 40; leg. 2536 c. V f. 30; leg. 2537 c. XIV f. 5; leg. 2558 c. IX f. 10; leg. 2561 c. V f. 28, c. VI fs. 1, 26; leg. 2564 c. III fs. 4, 5, 8, 27, 32; leg. 2565 c. V fs. 4, 6, 7, 9, 14, 15, 18, 22, 39, 45, c. VIII fs. 8, 10, 37, 79; leg. 2567 c. IV fs. $3,9,10,36,50$, c. XII fs. 1,2 , 18, c. XIII f. 12 ; leg. 2573 c. VI fs. 11,37 , 57; leg. 2577 c. IV f. 2; leg. 2585 c. VIII f. 27; leg. 2588 c. V f. 22; leg. 2589 c. V fs. 76, 153; leg. 2609 c. VI f. 66; leg. 2615 c. II fs. 7, 8, c. III f. 12; leg. 2616 c. III fs. 5, 9, 10, 22, 24, 35, 38, 44, 45, 46, 50, 88, 92, c. IV fs. 3, 18, 46; leg. 2617 c. I f. 77, c. III fs. 7, 10, 12; leg. 2618 c. I fs. $2,6,7,56$, c. II fs. $7,16,29$, c. III fs. 48, 51, 52, 53, 54bis, c. V fs. $1,2,22,42$; leg. 2619 c. I fs. 1,92 , c. II fs. $21,37,93$, c. III fs. 11,23 , c. IV f. 52 , c. V fs. $3,9,10,12,15$, c. VI fs. $3,7,34,54,87$, c. VII fs. 4, 57; leg. 2624 c. VIII f. 4 , c. XIII fs. $6,7,9,10,20,21,22,24,25,30,32,38,42,44,45,59,63,75,76,78$, $79,83,111,112,125,129,130$, c. XIV fs. 7, 9, 10, 34; leg. 2625 c. I fs. 7, 9, 31, 42, c. II f. 54, c. V fs. 4, 24, c. V f. 29, c. VI f. 25, c. IX f. 28; leg. 2626 c. I fs. 7, 60, c. III fs. $3,6,12,15$, c. V fs. $7,97,133$, c. IX f. 73 , c. XI fs. 9, 24, c. XII fs. 1, 26, c. XIII fs. 15, 61, 119, 123, 127, 128; leg. 2627 c. I fs. $6,9,19,20$, c. II fs. 37, 50, 51, 93, 98, c. III fs. $1,5,12,22,30,47$, c. V fs. $60,86,89$, c. VI fs. $1,3,5,10,12,18$, c. VIII fs. $2,20,56$, $57,59,67,91,92$, c. IX fs. $1,2,4,9,12,14,15,18,23$; leg. 2636 c. X fs. $1,3,5,38$, 39; leg. 2637 c. I fs. 1, 3, c. II fs. 8, 22, c. IV f. 7, c. V fs. 3, 7, 8, 24, 29; leg. 2639 c. II f. 40; leg. 2664 c. XVIII f. 40; leg. 2675 c. I f. 4; leg. 2848 c. IX f. 25.

Archivo General Militar de Segovia (en adelante AGMS), legs. A-260, A-274, B-121, B-122, B-248, B-1311, B-2227, B-3315, B-3368, C-2367, F-1239, I-364, P-2018, P-3102.

Esta special relationship permitió en los años siguientes a los grandes napolitanos conseguir puestos de relevancia fundamental al mando de las tropas borbónicas. Este fue el caso del mariscal de campo Giuseppe Acquaviva, marqués de Trepuzzi, cadete a los veinte años en 1734 en la Real Guardia de corps y un año después coronel del regimiento de infantería de Nápoles, brigadier de los reales ejércitos y comandante de la compañía de la Guardia de corps italiana ${ }^{27}$; del marqués Sebastiano Filangieri, coronel del regimiento de infantería de Milán y después brigadier en 176028; muy parecida fue la carrera militar de su consanguíneo, el marqués fray Antonio, coronel propietario del regimiento de infantería de Nápoles a los treinta y tres años en $1784^{29}$. Entre los otros grandes citaremos también el caso del coronel Giovanni Carrafa, cadete en la Real Compañía italiana de guardia de corps, coronel a los veintisiete años en $1785^{30}$. Recordaremos, todavía, entre los otros oficiales que empezaron sus

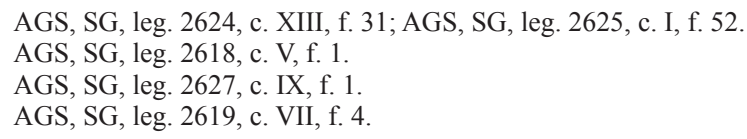


servicios en la compañía italiana de la guardia de corps y que después ascendieron a altos cargos en pocos años al coronel y brigadier Lorenzo Colonna, cadete en 1763 y coronel en 1778, a los treinta cuatro años de edad ${ }^{31}$; al coronel y brigadier Giuseppe Filomarino, cadete a los doce años, coronel a los veintinueve y brigadier poco después $^{32}$; al brigadier Vincenzo Imperiali, que después de pocos meses como cadete ingresó como capitán en el regimiento de caballería de Montesa y era general a los treinta seis $^{33}$; a Marco Antonio Morra, que era coronel del regimiento de caballería de Órdenes a los veintiocho y brigadier a los treinta y $\operatorname{cinco}^{34}$; al marqués Sersale, brigadier a los cuarenta, después de haber participado a la campaña de Portugal (1762) y en el sitio de Gibraltar (1779-1782) ${ }^{35}$.

Un comportamiento similar fue el de la gran nobleza siciliana, que ya en 1718, al desembarco de las tropas españolas en la isla, levantó un gran número de regimientos y compañías para el servicio de Felipe $\mathrm{V}$ en contra de los Saboya ${ }^{36}$. Estos fueron los casos de personajes como el coronel Giovanni Battista Gravina, comandante del regimiento de infantería de Palermo desde su formación, unidad que contribuyó a formar de su bolsillo ${ }^{37}$; o del coronel príncipe de San Pietro, de la primera nobleza siciliana, al mando del regimiento de infantería de Messina, otro grande que pagó la leva de tropas de su unidad ${ }^{38}$. El elenco de aristócratas isleños que en aquellos meses corrieron a servir bajo las banderas de los Borbones es impresionante. Recordemos al capitán y luego teniente coronel, Rosario Pietrasanta, hermano del coronel príncipe de San Pietro ${ }^{39}$, a Giovanni Matteo Valdina, que ingresó como capitán ${ }^{40}$, a los hermanos Termini -Ignazio, coronel comandante de un regimiento ${ }^{41}$, y Giuseppe, teniente coronel de la misma unidad y después del de Messina ${ }^{42}-$, al conde Gaspare Landolina, capitán y posteriormente teniente $\operatorname{corone~}^{43} \mathrm{o}$, finalmente, al capitán Luca Averna ${ }^{44}$.

Como los napolitanos, los grandes sicilianos en los años siguientes a 1738 consiguieron puestos de consideración en los reales ejércitos. Destacamos los casos

31 AGS, SG, leg. 2462, c. XII, f. 17.

32 AGS, SG, leg. 2619, c. I, f. 1.

33 AGS, SG, leg. 2627, c. VI, f. 3.

34 AGS, SG, leg. 2472, c. XXI, f. 135.

35 AGS, SG, leg. 2477, c. X, f. 1.

36 Con la paz de Rastadt (1714) el reino de Sicilia pasó a ser uno de los territorios de la casa de Saboya, a título de compensación por la contribución dada por parte de Piamonte a la guerra recién acabada. La actuación centralizadora de Victorio Amadeo II se enfrentó pronto con las peculiaridades locales y provocó un fuerte resentimiento entre los grandes sicilianos. Los vínculos mantenidos en estos años con la corte de Madrid han sido analizados por ÁlvAREzOssorio Alvariño, Antonio: «¿El final de la Sicilia española? Fidelidad, familia y venalidad bajo el virrey marqués de Los Balbases (1707-1713)», en Álvarez-Ossorio Alvariño, A. y otros (eds.): La pérdida de Europa. La guera de Sucesión por la Monarquía de España, Madrid, Fundación Carlos de Amberes, 2007, pp. 831-911, en particular pp. 900-903.

37 AGS, SG, leg. 2567, c. IV, f. 36.

38 AGS, SG, leg. 2567, c. XIII, f. 2.

39 AGS, SG, leg. 2565, c. VIII, f. 37

40 AGS, SG, leg. 2616, c. III, f. 5.

41 AGS, SG, leg. 2624, c. XIII, f. 45.

42 AGS, SG, leg. 2565 , c. V, f. 39.

43 AGS, SG, leg. 2616, c. IV, f. 6; leg. 2617, c. I, f. 42.

44 AGS, SG, leg. 2565, c. IV, f. 8. 
de Giuseppe de Gregorio, hijo de marqués, coronel a los veinte años en el regimiento de Parma, después de sólo cuatro años de servicio militar ${ }^{45}$; del coronel Manuel de Moncada, príncipe de Monforte, quien después de unos años de servicio en el ejército de Su Majestad siciliana pasó al del rey de España, llegando al grado de comandante del regimiento de dragones de Lusitania y de brigadier a los treinta y nueve años, inspector general de los dragones de España ${ }^{46}$; o el caso del coronel marqués de Vallesantoro, brigadier a los treinta y seis ${ }^{47}$.

Como Nápoles y Sicilia, también la Republica de Génova y el Ducado de Parma y Piacenza, que siguieron manteniendo, por varias razones, fuertes enlaces con la España borbónica, se destacaron en el panorama italiano por el servicio de sus élites a favor del rey de España. Génova lo hizo en virtud de sus fuertes vinculaciones políticas, dado que mantuvo una fuerte asociación con España y Francia hasta finales del siglo ${ }^{48}$. Una mancomunidad que vio actuar la República en ocasión de la guerra de Sucesión austriaca al lado de Francia y de España, cuando entró en guerra contra Austria y Saboya ${ }^{49}$. También lo hizo por sus antiguos y sólidos intereses económicos con la Península ibérica, donde sus banqueros y comerciantes continuaron a representar todavía en el siglo XVIII una de las comunidades mercantiles más floridas y España una de las principales bases para las inversiones del dinero ${ }^{50}$. Así que los apellidos de las grandes familias patricias de la ciudad se reencuentran a menudo en las hojas de servicio de la oficialidad borbónica, como los Balbi ${ }^{51}$, los Doria ${ }^{52}$, los

45 Cadete en 1744, subteniente el mismo año, teniente el año después y capitán en 1746, fue graduado coronel en 1748. Se señaló en ocasión de varios hechos de armas al tiempo de la guerra de Sucesión en Velletri (1744), toma de Piacenza y Tortona (1745) y en la batalla de Piacenza (1746): AGS, SG, leg. 2618, c. II, f. 29.

46 AGS, SG, leg. 2482, c. VII, f. 1; Molas Ribalta, Pere: «Virreyes italianos en la Corona de Aragón», en Martínez Millán y Rivero Rodríguez (coords.): op. cit. (nota 1), vol. I, pp. 31-55.

47 Después de haberse señalado en varias ocasiones como en la sorpresa de Velletri (1744), la toma de Piacenza (1745) y la batalla que siguió el año después: AGS, SG, leg. 2618, c. V, f. 2.

48 Sobre la política de la República ligur en el siglo XVIII, y su fuerte vinculación con los reinos borbónicos a pesar de su neutralidad, remito a los trabajos de Costantini, Claudio: La Repubblica di Genova, Turín, UTET Libreria, 1986, pp. 419 y ss.; Bıтоssi, Carlo: La Repubblica è vecchia: patriziato e governo a Genova nel secondo Settecento, Roma, Istituto storico italiano per l'età moderna e contemporánea, 1995.

49 Sobre esta participación activa en la guerra de Sucesión al lado de Francia y de España véase VeNTURI: $o p$. cit. (nota 1, 1969), pp. 198 y ss. En general, para la historia de esta guerra véase Melandreras Gimeno, María del Carmen: Las campañas de Italia durante los años 1743-1748, Murcia, Universidad de Murcia, 1987. Como también las recientes obras de Anderson, Matthew Smith: The War of the Austrian Sucession 1740-1748, Londres, Longman, 1995; Browning, Reed: The war of the Austrian Succession, Nueva York, St. Martin's Press, 1993; y Harding, Richard: The Emergence of Britain's Global Naval Supremacy. The War of 1739-1748, Woodbridge, The Boydell Press, 2010.

50 Felloni, Giuseppe: Gli investimenti finanziari genovesi in Europa tra il Seicento e la Restaurazione, Milán, A. Giuffrè, 1971.

51 Con el capitán Giovanni Luca, voluntario en la guerra de Sucesión polaca donde se distinguió en los sitios de los castillos de Nápoles, batalla de Bitonto (1734), sitios de Messina y Siracusa y en la campaña de Lombardía: AGS, SG, leg. 2624, c. XIII, f. 7.

52 Como el teniente coronel Agostino, que ingresa directamente como teniente coronel, después de unos años de servicio en el ejército francés, en ocasión de la campaña italiana de 1718 en el regimiento de Elvetia (AGS, SG, leg. 2616, c. III f. 50). 
Spínola ${ }^{53}$, los Roncalli ${ }^{54}$, los Giovio ${ }^{55}$ o los Zoagli ${ }^{56}$. En cuanto al Ducado de Parma y Piacenza, los enlaces matrimoniales y la radicación en el territorio de otra rama de los Borbones ${ }^{57}$ favoreció la llegada de un cierto número de segundones, aunque no sólo de ellos, que buscaban empleo en las armas reales ${ }^{58}$.

Seguramente, respecto a otros territorios tradicionalmente vinculados con la España del Siglo de las Luces, resultan más sorprendentes los datos referidos a la fuerte presencia de toscanos, lombardos y piamonteses en los reales ejércitos. Si la Toscana era considerada una posesión de los Lorenas -y desde el punto de vista puramente jurídico un territorio distinto a los de la monarquía de los Austrias vieneses-, desde el punto de vista estratégico y estrictamente militar dependía en todo y por todo de Viena, que lo administraba por vía de un consejo particular ${ }^{59}$. En realidad, el Gran Ducado representaba una especie de anillo débil en el panorama de los intereses de los Habsburgo, dado que siempre existió en este territorio un fuerte partido español que pesó en la vida política de Florencia y de las otras ciudades en los años treinta y cuarenta del XVIII ${ }^{60}$. Un hecho que permitió a los Borbones aprovecharse de la situación y poder efectuar varias levas en la región con la benévola complicidad de los poderosos locales ${ }^{61}$. Aristócratas que consiguieron en algunas ocasiones puestos particulares en las fuerzas de la corona, como Pietro Guelfi, miembro de una de las principales familias de Arezzo, que llegó a ser coronel propietario del regimiento de Nápoles y brigadier ${ }^{62}$. Se puede afirmar que la presencia de un constante estado de emergencia y de guerra en estos años permitió a los nobles y patricios toscanos de utilizar la carta del servicio al rey de España, y en particular en los ejércitos empeñados en las luchas por la supremacía de Italia,

53 Recordemos el teniente coronel Alessandro (AGS, SG, leg. 2619, c. VI, f. 7).

54 Con el coronel conde Giovanni Michele, comandante del regimiento de Toscana levantado en 1718 (AGS, SG, leg. 2624, c. XIII, f. 44).

${ }_{55}$ Con el capitán Giovanni Battista, oficial en tiempo de Carlos III que se distinguió en la defensa del Peñón de Vélez (1775), en el sitio del fuerte de San Felipe en Menorca y en el de Gibraltar (AGS, SG, leg. 2627, c. VIII, f. 20).

56 Con el capitán Giovanni Battista (AGS, SG, leg. 2626, c. I, f. 7).

57 Tocci, Giovanni: «Il Ducato di Parma e Piacenza», en Marini, Lino y otros: I Ducati padani, Trento e Trieste, Turín, UTET, 1979, pp. 286-317.

58 Como el teniente coronel Evangelista Tarrasconi, de familia ilustre del Parmesano, que ingresó como cadete en 1735 y todavía se encontraba en servicio en 1783 (AGS, SG, leg. 2627, c. VIII, f. 2); como Luigi Soprani, cadete en el Real Colegio de Artillería de Segovia (1765), capitán de dicha arma y teniente coronel de infantería (AGS, SG, leg. 411, f. 125); como el coronel marqués de Gualengo, agregado al regimiento de Nápoles y ayudante de campo del marqués de Crillón con ocasión del sitio de Gibraltar (AGS, SG, leg. 2627, c. IX, f. 4); o, por último, el placentino Geronimo de Leoni, teniente coronel de artillería (AGS, SG, leg. 411, f. 196).

59 WAQUeT, Jean-Claude: «La Toscane après la paix de Vienne (1737-1765): prépondérance austrichenne ou absolutisme lorrain?», Revue d'Histoire Diplomatique, XCIII (1979), pp. 1-21 ; CHAPRon, Emmanuelle: «Lo stato degli Asburgo-Lorena (1737-1799)», en BoutIER, J. y otros (eds.): Firenze e la Toscana. Genesi e trasformazione di uno stato (XIV-XIX secolo), Florencia, Mandragora, 2010, pp. 87-103.

${ }_{60}$ Contini, Alessandra: La reggenza lorenese fra Firenze e Vienna. Logiche dinastiche, uomini e governo (17371766), Firenze, Leo C. Olschki, 2002. Sobre los Lorena, grandes duques de Toscana, véase también VERGA, Marcello: Da "cittadini" a "nobili". Lotta politica e riforma delle istituzioni nella Toscana di Francesco Stefano, Milán, Giuffrè, 1990.

${ }_{61}$ Destaquemos, entre otros, al capitán conde Guglielmo Boldrini, de Montepulciano (AGS, SG, leg. 2561, c. VIII, f. 1), a Giovanni Guadalberto Del Riccio, de Florencia, capitán en el regimiento de Nápoles (AGS, SG, leg. 2624, c. XIII, f. 7), y a Federico Ruccellai, también de Florencia, que acabó siendo coronel en los años sesenta (AGS, SG, leg. 2627, c. I, f. 9).

${ }^{62}$ AGS, SG, leg. 2627, c. III, f. 1. 
como atout en sus conflictos con los nuevos gobernantes de la casa de Lorena, con el fin último de poder conservar o ampliar sus redes de poder e intereses ${ }^{63}$.

Sin embargo, y al contrario de lo que generalmente se cree, la unión de los intereses de varias familias toscanas con España no se acabó con la guerra de Sucesión austriaca, ni con la radicación en el territorio de la dinastía de los Habsburgo-Lorena y el fin de la política italiana de Felipe V con el tratado de Aranjuez y la nueva entente entre Borbones y Habsburgos. En los años siguientes varios miembros de la nobleza provinciana siguieron mirando a Madrid para obtener puestos en las fuerzas armadas españolas ${ }^{64}$. Algunos de ellos, siguiendo las huellas de otros miembros de su familia, ingresaron así en el ejército borbónico, como Francesco Guelfi, capitán comandante de un escuadrón de caballería en el regimiento de Montesa, y que se señaló en la campaña de Portugal y en el sitio de Gibraltar ${ }^{65}$; o como Ulisse Albergotti, ingresado como cadete en 1764, coronel del regimiento de Nápoles en 178966; o como los Malaspina de la Lunigiana, que vieron a varios miembros de la familia lucir el uniforme de los Borbones ${ }^{67}$.

La fuerte presencia de varios oficiales pertenecientes a las principales familias lombardas, también después de 1707 -año en el que el Milanesado cayó en manos de los austriacos-, es otro indicio que nos permite aclarar que todavía en la región siguieron existiendo fuertes vínculos de sus élites con la corte de Madrid ${ }^{68}$. Si es verdad que algunos de los oficiales que se quedaron en las fuerzas armadas de Felipe $\mathrm{V}$ eran viejos veteranos -algunos de ellos ya en armas desde los últimos años del reinado de Carlos II $^{69}$-, la verdadera edad de oro del servicio de los grandes lombardos esta representada por las guerras de Italia de los años treinta y cuarenta del XVIII, que vieron una fuerte movilización de las élites locales presentes en ambos bandos ${ }^{70}$. Son

${ }^{63}$ A este propósito no parece un caso que muchos de los partidarios de España consiguieran varias plazas de relevancia en el gobierno del estado en estos años gracias a la política de Francesco Stefano de Lorena: ConTINI: op. cit. (nota 60), pp. 89-224.

${ }_{64}$ Todavía en los años setenta y ochenta siguieron ingresando personajes de la alta sociedad toscana en los regimientos del rey. Destacamos a Beniamino Sproni de Livorno (AGS, SG, leg. 2619, c. VII, f. 54), a Francesco Simonetti de Florencia en la guardia de corps (AGS, SG, leg. 2504, c. XVII, f. 40), y a Clemente Griffi, también de Florencia (AGS, SG, leg. 2509, c. V, f. 141).

${ }^{65}$ AGS, SG, leg. 2484, c. IX, f. 75.

66 AGS, SG, leg. 2627, c. IX, f. 2.

67 AGS, SG, leg. 2464, c. VII, f. 115; leg. 2589, c. V, f. 153.

68 Un hecho generalmente pasado bajo silencio. En uno de los mejores manuales sobre la historia de la Lombardía austriaca (CAPRA, Carlo: La Lombardia austriaca nell'etá delle riforme 1706-1796, Turín, UTET libreria, 2001, reimpresión del original de 1987) no se habla en ninguna ocasión de los fuertes enlaces entre la nobleza milanesa y España que prosiguieron todavía después de 1707.

69 Recordemos a Domenico Giorgio Traggia, quien se alistó en 1691 y acabó siendo gobernador de la ciudad de Balaguer, con sus hijos naturalizados españoles que prosiguieron el servicio del rey en las décadas siguientes: Andúdar Castillo: op. cit. (nota 13), pp. 132-133; Andújar CAstillo, Francisco: El sonido del dinero. Monarquía, ejército y venalidad en la España del siglo XVIII, Madrid, Marcial Pons, 2004, p. 252; o al teniente coronel conde Giuseppe Caimi, activo desde 1702 que en 1756 estaba todavía sirviendo en el regimiento de dragones de Numancia (AGS, SG, leg. 2485, c. IX, f. 5); al conde de Ripa, quien entró en el ejército en los últimos días de la dominación española y que pasó toda una vida al servicio de las armas (AGS, SG, leg. 2503, c. VIII, f. 11); a Giuseppe Beccaria, otro veterano de las guerras de Carlos II (AGS, SG, leg. 2465, c. II, f. 6); o, por último, a Giuseppe Alliora, de Alessandria, quien se alistó en 1702 en el tercio del conde Francesco Bonesana y ascendió todo el escalafón hasta la plaza de sargento mayor en el regimiento de Palermo (AGS, SG, leg. 2616, c. III, f. 26).

70 Por ejemplo los Visconti o los Borromeo, que sirvieron en el ejército imperial y en el español. Sobre la oficialidad lombarda al servicio del Imperio véanse DufFY: op. cit. (nota 8, 1977); y Donati: op. cit. (nota 7, 1982). 
años en los cuales no es sorprendente ver algunos exponentes de la misma familia en los dos bandos contrapuestos, fruto de una elaborada estrategia actuada ya a finales del siglo XVII y principios del siguiente ${ }^{71}$. Una estrategia que hundía sus raíces ya en las primeras décadas del siglo XVI, cuando muchas casas nobiliarias se dividieron entre partidarios del rey de Francia y del emperador ${ }^{72}$, previendo así -por el bien y la preservación del patrimonio- el no tomar un único partido, sino dividir a sus exponentes entre los varios bandos en lucha ${ }^{73}$. En estos años se señalaron personajes como el conde Borromeo, quien llegó a ocupar en 1736, a los veinte y dos años de edad, el grado de coronel del regimiento de Milán ${ }^{74}$; Antonio Litta, de la noble casa milanesa de este apellido, que participó a varios hechos de armas como la batalla de Camposanto y de Piacenza ${ }^{75}$; el conde Vittorio Bolognini Attendolo, quien llegó al grado de brigadier a los treinta y cuatro años, en plena guerra de Sucesión austriaca, donde participó en varios encuentros y batallas y trató la rendición de la plaza de Tortona (1746) a los austro-sardos ${ }^{76}$. También podemos recordar a Giovanni Antonio Visconti, otro segundón de una de las principales familias del Ducado ${ }^{77}$, o a Santiago Corio, que ingresó como guardia de corps y pasó después a servir en la caballería ${ }^{78}$.

Una tradición de servicio que no acabó con el fin de las guerras de Italia, dado que en los años del reinado de Fernando VI y Carlos III todavía muchos de los pertenecientes a la buena sociedad milanesa siguieron ingresando en los reales ejércitos. Personajes como el conde Turconi, que entró directamente como capitán en el regimiento de dragones de Edimburgo ${ }^{79}$, o el conde Antonio Maggiolino, caballero principal del ducado, que a los veinte años era teniente en el regimiento de infantería de Milán ${ }^{80}$; o el conde Giuseppe Attendolo Bolognino, otro miembro de una de las más antiguas familias de la nobleza lombarda ${ }^{81}$. Sobre todo destacamos los casos

\footnotetext{
71 Cuando muchos de los grandes de Milán, en previsión de una división de la herencia de Carlos II, empezaron a repartirse en dos bandos fieles a los Borbones y a los Austrias de Viena. Cremonini, Cinzia: «El príncipe de Vaudemont y el gobierno de Milán durante la guerra de Sucesión española», en Álvarez-Ossorio Alvariño y otros: op. cit. (nota 36), pp. 463-490.

${ }^{72}$ Chabod, Federico: Storia di Milano nell'epoca di Carlo V, Turín, Einaudi, 1971. Y que prosiguió en la segunda mitad del siglo con varios milaneses que siguieron prestando sus servicios al rey de Francia: PARROTT, David: «Italian Soldiers in French Service, 1500-1700. The Collapse of a Military Tradition», en BiAnchi y otros: op. cit. (nota 13), pp. 15-39.

73 Esta política fue utilizada a menudo por parte de las élites de las regiones de "frontera", áreas estratégicas como los Países Bajos meridionales o el norte de Italia, o territorios largamente disputados como podían ser el Reino de Nápoles o Escocia e Irlanda, donde las élites vieron a sus miembros servir contemporáneamente en distintos ejércitos. De este modo, una familia flamenca, milanesa o napolitana podía mantener a varios de sus exponentes en armas en el Imperio, en España o en Francia y una irlandesa o escocesa servir al mismo tiempo al rey de Gran Bretaña y a sus oponentes. Para la actuación de una estrategia similar en el reino de Nápoles véase Spagnoletti: op. cit. (nota 22); para Flandes, si bien con referencia al siglo anterior, VERMEIR, René: «Je t'aime, moi non plus. La nobleza flamenca y España en los siglos XVI-XVII», en Yun Casalilla, B. (ed.): Las redes del Imperio. Élites sociales en la articulación de la Monarquía Hispánica, 1492-1714, Madrid, Marcial Pons-Universidad Pablo de Olavide, 2009, pp. 313-337.

74 Y que sólo dos años antes había empezado su vida militar ingresando en la compañía italiana de las guardias de corps: AGS, SG, leg. 2616, c. III, f. 44.

75 AGS, SG, leg. 409, f. 181.

76 AGS, SG, leg. 2618, c. I, f. 27; leg. 2618, c. III, f. 54bis.

77 AGS, SG, leg. 2637, c. V, f. 24.

78 AGS, SG, leg. 2504, c. III, f. 7.

79 AGS, SG, leg. 2476, c. XIV, f. 8.

${ }^{80}$ AGS, SG, leg. 2618, c. III, f. 53.

${ }^{81}$ AGS, SG, leg. 2618, c. III, f. 52.
} 
de los dos Beccaria, ambos de nombre Pietro, primos del celebrado autor de Dei delitti e delle pene y segundones de una de las más notables casas de la nobleza de la Lombardía $^{82}$.

Como en el caso de los milaneses, también fue significativa la constante presencia de los nobles piamonteses entre las filas de los ejércitos reales. Supuestamente, el desarrollo de un fuerte estado militar en Piamonte y Saboya habría llevado a la élite local a transformarse a lo largo de los siglos XVII y XVIII en una aristocracia de servicio fuertemente vinculada a la dinastía ducal. En realidad, la nobleza de las provincias de nueva adquisición (Novara, Alessandria, Tortona), miraban al nuevo gobierno centralizado piamontés con sentimientos de sustancial extrañeza, si no de hostilidad, y los grupos dirigentes de estos territorios siguieron mirando a lo largo de todo el siglo XVIII a Milán, Madrid y Viena más que a Turín. En el curso de la guerra de Sucesión austriaca gran parte de la nobleza de estas tierras no consideraba todavía ineluctable el destino piamontés, recusando su ingreso en las estructuras administrativas y militares del estado de los Saboya ${ }^{83}$. En estos años, como también después del fin de la guerra, fueron varios los oficiales de Alessandria que sirvieron en los regimientos españoles, personajes como Giovanni Giacomo Civalieri ${ }^{84}$, Giulio Cesare Marsari ${ }^{85}$ o el coronel Camillo Sardi ${ }^{86}$.

Pero no sólo desde las antiguas provincias del Estado de Milán ingresaron en estos años varios oficiales de origen aristocrático en las fuerzas reales, sino también desde otros territorios de los estados piamonteses. Personajes como el coronel Carlo Sacchetti de Turín, que empezó a servir en 1743 en Italia en el arma de artillería ${ }^{87}$, el teniente coronel Gaspare Del Bove, oficial de la Real Brigada de carabineros ${ }^{88}$, el coronel Enrico De Stefani ${ }^{89}$, y los dos hermanos Balbiani, Cesare y Raffaele, miembros de una distinguida familia de $\mathrm{Asti}^{90}$.

El origen social de estos oficiales denota, en su gran mayoría, y como ya se ha anticipado en las páginas anteriores, su proveniencia de las filas de la aristocracia (véase cuadro II). De los 310 casos estudiados, los pertenecientes a las clases más bajas representan sólo el $6,45 \%$ del total, un porcentaje que sube al 13,22\% considerando los indicados como hijos de oficiales ${ }^{91}$. Generalmente los soldados de fortuna, los de humilde origen o condición, se quedaban años sirviendo en los

32 AGS, SG, leg. 2470, c. I, f. 36; leg. 2483, c. II, f. 30.

83 En estos años, en Alessandria, a la llegada de las tropas españolas (1745), muchos de los patricios y nobles ciudadanos abrazaron la causa de los Borbones en la esperanza de una vuelta de la ciudad a la soberanía española. La vuelta de los Saboya (1746) provocó el encarcelamiento de gran parte de los dirigentes ciudadanos bajo la acusación de connivencia con el enemigo. Sobre estos problemas remito a Merlotti: op. cit. (nota 2), pp. 77, 139 y ss.

${ }^{84}$ AGS, SG, leg. 2619, c. II, f. 37.

85 AGS, SG, leg. 2466, c. III, f. 10.

86 AGS, SG, leg. 2478, c. II, f. 1.

87 AGS, SG, leg. 410, f. 5.

88 AGS, SG, leg. 2468, c. XIII, f. 14

89 AGS, SG, leg. 2492, c. XII, f. 2.

90 AGS, SG, leg. 2619, c. V, f. 12; leg. 2619, c. VI, f. 34.

91 Sin embargo hay que tener en cuenta el hecho de que en varias ocasiones los padres de estos últimos pertenecían a la nobleza, como Pietro Lavelli, hijo del coronel comandante del regimiento de caballería de Mérida, Antonio Lavelli, nativo de Milán y de calidad ilustre (AGS, SG, leg. 2475, c. I, f. 36 y c. II, f. 1), o Gaetano Lettieri, hijo de un mariscal de campo perteneciente a la nobleza napolitana (AGS, SG, leg. 2522, c. XI, f. 3). 
puestos marginales del escalafón, casi sin ninguna posibilidad de ascenso, y que en los mejores casos llegaban al grado de capitán después de varios años de milicia ${ }^{92}$. Como hemos visto, si los soldados profesionales acababan su carrera en posiciones marginales, más rápida parecía la carrera de los pertenecientes a la gran aristocracia italiana y no sólo de aquellos procedentes de los territorios vinculados de alguna manera a la Monarquía española, de los que hemos hablado en las páginas anteriores.

\section{Cuadro II. Calidad de los oficiales italianos}

\begin{tabular}{|lc|}
\hline Calidad & \\
\hline Muy conocida & 2 \\
Nobleza conocida & 2 \\
Conocida & 77 \\
Noble & 48 \\
Ilustre & 22 \\
Notoria & 3 \\
Hijo de príncipe & 1 \\
Hijo de duque & 1 \\
Hijo de grande & 1 \\
Hijo de marqués & 1 \\
Hidalgo & 19 \\
Caballero principal & 2 \\
Caballero conocido & 2 \\
Caballero & 40 \\
Honrada & 4 \\
Distinguida & 17 \\
Hijo de oficial & 21 \\
Buena & 26 \\
Bien nacido & 1 \\
Mediana & 9 \\
Ciudadano & 1 \\
Hijo de abogado & 1 \\
Civil & 2 \\
Soldado de fortuna & 6 \\
Desconocida & 1 \\
TOTAL & \\
\hline
\end{tabular}

\footnotetext{
92 Como Giovanni Gola, soldado de fortuna que sólo después de 33 años de vida militar consiguió la graduación de capitán (AGS, SG, leg. 2624, c. XIV, f. 7); o de Giacomo Granelli, otro villano que a los 44 años era todavía subteniente (AGS, SG, leg. 2619, c. IV, f. 52); o Giovanni Battista Milani, veneciano, que obtuvo los grados de capitán después de 23 años de servicios y a los 59 años era todavía capitán de artillería (AGS, SG, leg. 409, f. 48).
} 
Fuentes: AGS SG leg. 407 fs. 161, 163, 209, 215, 256, 323, 617, 635; leg. 408 fs. 68, 223, 393; leg. 409 fs. 20, 48, 113, 181, 231; leg. 410 fs. 5, 7, 12, 28; leg. 411 fs. 125, 150, 196, 214; leg. 2462 c. II f. 12, c. XII f. 17; leg. 2464 c. II f. 33, c. III f. 6, c. VII f. 115; leg. 2465 c. II f. 6, c. IV f. 4, c. V f. 5; leg. 2466 c. I f. 12, c. III f. 10; leg. 2467 c. II f. 3; leg. 2468 c. XIII fs. 5, 14; leg. 2469 c. II f. 13, c. V f. 2; leg. 2470 c. I f. 36; leg. 2471 c. VIII f. 2, c. XII f. 34, c. XVIII f. 6; leg. 2472 c. XII f. 8, c. XIII f. 7, c. XXI fs. 135, 136; leg. 2474 c. VIII fs. 21, 46; leg. 2475 c. II fs. 1, 36, c. III f. 23; leg. 2476 c. XIV f. 8; leg. 2477 c. X fs. 1, 22; leg. 2478 c. I f. 18, c. II f. 1; leg. 2479 c. I f. 4; leg. 2480 c. I f. 1, c. III f. 7; leg. 2482 c. VII f. 1; leg. 2483 c. II fs. 30, 40; leg. 2484 c. VIII f. 1, c. IX f. 75; leg. 2485 c. IX f. 5; leg. 2489 c. III f. 15, c. IV f. 53, c. VIII f. 5, c. IX f. 17 , c. XI fs. 11, 14; leg. 2492 c. II f. 11, c. VII f. 17, c. X f. 25, c. XII f. 2, c. XIII f. 22; leg. 2493 c. VI f. 23, c. VII f. 27; leg. 2494 c. IV f. 3; leg. 2495 c. II f. 9, c. VI f. 39; leg. 2503 c. II fs. 1, 11; leg. 2504 c. III f. 7, c. XVII f. 40; leg. 2509 c. V f. 141, c. VIII fs. 21, 36; leg. 2515 c. VI f. 6; leg. 2521 c. II f. 69; leg. 2522 c. V f. 3, c. XI fs. 3, 27; leg. 2527 c. VII f. 13; leg. 2531 c. V f. 40; leg. 2536 c. V f. 30; leg. 2537 c. XIV f. 5; leg. 2558 c. IX f. 10; leg. 2561 c. V f. 28, c. VI fs. 1, 26; leg. 2564 c. III fs. 4, 5, 8, 27, 32; leg. 2565 c. V fs. 4, 6, 7, 9, 14, 15, 18, 22, 39, 45, c. VIII fs. 8, 10, 37, 79; leg. 2567 c. IV fs. $3,9,10,36,50$, c. XII fs. $1,2,18$, c. XIII f. 12 ; leg. 2573 c. VI fs. 11,37 , 57; leg. 2577 c. IV f. 2; leg. 2585 c. VIII f. 27; leg. 2588 c. V f. 22; leg. 2589 c. V fs. 76, 153; leg. 2609 c. VI f. 66; leg. 2615 c. II fs. 7, 8, c. III f. 12; leg. 2616 c. III fs. 5, 9, $10,22,24,35,38,44,45,46,50,88,92$, c. IV fs. 3, 18, 46; leg. 2617 c. I f. 77, c. III fs. 7, 10, 12; leg. 2618 c. I fs. 2, 6, 7, 56, c. II fs. 7, 16, 29, c. III fs. 48, 51, 52, 53, 54bis, c. V fs. $1,2,22,42$; leg. 2619 c. I fs. 1,92 , c. II fs. $21,37,93$, c. III fs. 11,23 , c. IV f. 52 , c. V fs. $3,9,10,12,15$, c. VI fs. $3,7,34,54,87$, c. VII fs. 4, 57; leg. 2624 c. VIII f. 4 , c. XIII fs. $6,7,9,10,20,21,22,24,25,30,32,38,42,44,45,59,63,75,76,78$, $79,83,111,112,125,129,130$, c. XIV fs. 7, 9, 10, 34; leg. 2625 c. I fs. 7, 9, 31, 42, c. II f. 54 , c. V fs. 4, 24, c. V f. 29, c. VI f. 25, c. IX f. 28; leg. 2626 c. I fs. 7, 60, c. III fs. $3,6,12,15$, c. V fs. $7,97,133$, c. IX f. 73 , c. XI fs. 9, 24, c. XII fs. 1, 26, c. XIII fs. 15, 61, 119, 123, 127, 128; leg. 2627 c. I fs. $6,9,19,20$, c. II fs. 37, 50, 51, 93, 98, c. III fs. $1,5,12,22,30,47$, c. V fs. $60,86,89$, c. VI fs. $1,3,5,10,12,18$, c. VIII fs. $2,20,56$, $57,59,67,91,92$, c. IX fs. $1,2,4,9,12,14,15,18,23$; leg. 2636 c. X fs. $1,3,5,38$, 39; leg. 2637 c. I fs. 1,3 , c. II fs. 8, 22, c. IV f. 7, c. V fs. 3, 7, 8, 24, 29; leg. 2639 c. II f. 40; leg. 2664 c. XVIII f. 40; leg. 2675 c. I f. 4; leg. 2848 c. IX f. 25.

AGMS legs. A-260, A-274, B-121, B-122, B-248, B-1311, B-2227, B-3315, B-3368, C-2367, F-1239, I-364, P-2018, P-3102

El conde Malfatti de Verona ingresó directamente como capitán en 1746 sin ninguna experiencia previa en el ejército y sirvió en las campañas de Italia y Provenza de 1746-48 y en la guerra de Portugal (1762), terminando sus servicios como corone $^{93}$. Más espectacular fue la carrera de Orazio Borghese, personaje destacado de esta ilustre familia romana (su padre, el príncipe Camillo Borghese, además de unos cuantos títulos nobiliarios italianos gozaba también del rango de Grande de España). Fue admitido en la guardia de corps en 1754 y en el mismo año ya lucía los galones de teniente coronel, en servicio en la guerra de los Siete Años en los ejércitos franceses (donde tuvo parte en las infaustas campañas de Alemania septentrional de

93 AGS, SG, leg. 2494, c. IV, f. 3. 
1761 y 1762 , marcadas por una serie de derrotas humillantes frente a las fuerzas de Fernando de Brunswick y en las operaciones contra Portugal de $1762^{94}$ ). De vuelta a España, consiguió la plaza de coronel del regimiento de Montesa en 1764 y después la plaza de brigadier, cubriendo importantes encargos diplomáticos como embajador en Prusia ${ }^{95}$.

La presencia de este gran número de aristócratas italianos entre las filas de los reales ejércitos creó a lo largo de todo el siglo un formidable grupo de presión para favorecer los intereses de los personajes vinculados con ellos ${ }^{96}$. Los napolitanos, y en menor medida los otros italianos, en servicio en la compañía de la guardia de corps como ya hemos recordado, se vieron favorecidos y consiguieron en pocos años plazas muy señaladas en el mando de las tropas ${ }^{97}$. Además, gracias a una atenta política matrimonial varios de ellos consiguieron no sólo naturalizarse como españoles sino radicarse en la alta sociedad castellana. Recordemos a Vincenzo Maria Imperiali, originario de Génova, marqués de Latiano, militar y diplomático ${ }^{98}$; a su hijo, el mariscal de campo Vincenzo, quien enlazó con María Antonia Cattaneo Boncompagno, hija del príncipe de San Nicandro, grande de España y caballerizo mayor del rey Carlos III ${ }^{99}$; o a los duques de Castropignano, que vieron a sus miembros gozar de importantes cargos en los ejércitos españoles (tenientes generales, coroneles comandantes de la compañía italiana de la guardia de corps) y del reino de Nápoles ${ }^{100}$.

Sin embargo, fueron los Pignatelli, condes de Fuentes, una familia originaria del reino de Nápoles con una gran tradición militar al servicio de los Austrias, con ramificaciones en Sicilia y España, quienes iban a conseguir a lo largo del XVIII, gracias también a una exitosa política matrimonial, unas posiciones de particular prestigio en la corte española. Antonio Pignatelli fue mariscal de campo, teniente general en ocasión de la empresa de Cerdeña (1717) y de Sicilia (1718) ${ }^{101}$; Francesco fue gobernador militar de Zaragoza entre 1740 y 1742; y Gaetano Maria obtuvo al final de la guerra de Sucesión austriaca el mando del regimiento de infantería

94 Él mismo participó a la batalla de Vellinghausen y a la retirada de Kassel, dos de los principales hechos de armas en los cuales los franceses se vieron derrotados por parte de las fuerzas anglo-alemanas: SzABo, Franz A.J.: The Seven Years War in Europe 1756-1763, Londres, Longman, 2008, pp. 350-361, 408-411. La acción francoespañola contra Portugal, tradicional aliado de Gran Bretaña, también acabó en un rotundo fracaso gracias no sólo a la resistencia portuguesa, sino también a la llegada de poderosos refuerzos británicos y a la pésima conducción de las operaciones por parte aliada. BAugh, Daniel: The Global Seven Years War 1754-1763, Londres, Longman, 2011, pp. 590-598. Sobre esta guerra véase también GonzÁlez Enciso, Agustín: «Spain's Mobilization of Resources for the War with Portugal in 1762», en Bowen, H.V. y González Enciso, A. (eds.): Mobilising Resources for War: Britain and Spain at Work During the Early Modern Period, Pamplona, EUNSA, 2006, pp. 159-189.

95 AGS, SG, leg. 2484, c. VIII, f. 1. Sobre su carrera como embajador véase Ozanam, Didier: Les diplomates espagnols du XVIII siècle, Madrid y Burdeos, Casa de Velázquez-Maison des Pays Ibériques, 1998, p. 192.

96 Personajes como Tiberio Carafa, que dominó el escenario de la corte en los primeros decenios del reinado de Felipe V, o Francesco Pio de Saboya, que acompañó a la joven Maria Luisa de Saboya a Madrid y en pocos años se ganó plazas de considerable valor en la corte: AndúJAR CASTILLO: op. cit.(nota 13), pp. 130-132.

${ }_{97}$ Sobre la importancia del servicio en la guardia de corps para conseguir el favor real remito a las consideraciones de AndúJar CAstillo: op. cit.(nota 13), pp. 109 y ss.

98 Ozanam: op. cit. (nota 95), p. 300.

99 AGMS, leg. I-364 (Vincenzo Imperiali).

100 AGMS, leg. C-2367 (duques de Castropignano).

101 Personaje peculiar, pasó después a servir en el ejército imperial y fue el general al mando de las tropas austriacas en la batalla de Bitonto (1734): Molas Ribalta: op. cit. (nota 46), p. 53. 
de Nápoles con solo diecinueve años de edad ${ }^{102}$. Como él, Giovanni Domenico estuvo al mando del mismo regimiento para ser ascendido después a la plaza de brigadier y mariscal de campo, embajador en Dinamarca y en Parma ${ }^{103}$. Por último, recordaremos a los dos tenientes generales Giovanni Domenico y Armando, hijos de Gioacchino Atanasio, quien fue un eminente diplomático, embajador en Turín, Londres y París, caballero del Toisón de Oro, y de Maria Luigia Gonzaga, duquesa de Solferino, grande de España de primera clase y dama de palacio. El primero se casó con María Trinidad, hija de Eduardo Wall ${ }^{104}$, teniente general de los reales ejércitos y de doña María Concepción Manrique de Lara. Hizo una brillante carrera militar y consiguió el mando del ejército de Castilla la Nueva al tiempo de la guerra de la Independencia, donde fue preso y procesado en 1810 por haber abandonado las ciudades de Valladolid y Ávila sin ofrecer resistencia, un "escandaloso y cobarde abandono", según la acusación ${ }^{105}$. La investigación no dio sin embargo resultado alguno y Giovanni Domenico consiguió recuperar su posición en los reales ejércitos y en los años siguientes siguió luchando contra los franceses. El segundo, Armando, heredero de los títulos y bienes de los condes de Fuentes, llegó también a asumir posiciones de gran importancia en el ejército español gracias a las protecciones en la corte. Una carrera que se acabó de repente con la guerra de la Independencia cuando, partidario de José Bonaparte y noto afrancesado, Armando Pignatelli fue encarcelado y privado de sus bienes ${ }^{106}$.

Además de estos casos excepcionales, otros también consiguieron naturalizarse como españoles, dando así origen a verdaderas dinastías militares hispano-italianas. Los ejemplos en este sentido no faltan. Los ya citados Balbiani dieron lugar a tres generaciones de soldados al servicio del rey. El conde Gaetano Balbiani, oficial del rey, se casó con doña Magdalena Gómez de Quiñones y vio a sus hijos alcanzar posiciones de particular relevancia en la administración civil, con Luigi que alcanzó ser alguacil mayor de la real audiencia de Pamplona, y Cesare, oficial de infantería, que enlazó con doña Tadea de Sesma y Saraza, natural de Pamplona, hija única del licenciado Miguel de Sesma, abogado de las audiencias reales del reino de Navarra, fiscal interino del consejo y auditor de guerra ${ }^{107}$. Su hijo Gaetano ingresó también él en el ejército, consiguiendo a los 12 años la plaza de subteniente en el ejército de América ${ }^{108}$. La rama del conde Maurizio vio como Angelo Carlo Gaetano ingresaba en los reales ejércitos y contraía matrimonio con Magdalena Jiménez, natural del reino de Valencia; su hijo, Raffaele, siguiendo las huellas de la familia fue también militar,

102 AGS, SG, leg. 2625, c. IX, f. 28.

103 Ozanam: op. cit. (nota 95), pp. 394-395; AGS, SG, leg. 2625, c. V, f. 29.

104 Pariente lejano de Ricardo Wall, uno de los militares irlandeses más renombrados de la corte de Carlos III y que pasó del servicio de Francia al de España en 1750, donde hizo una brillante carrera militar gracias también a su bien pensada política matrimonial: Téllez Alarcia, Diego: D. Ricardo Wall. Aut Caesar aut nullus, Madrid, Ministerio de Defensa, 2008, pp. 53-54.

105 AGMS, leg. P-2018 (Giovanni Domenico Pignatelli).

106 Un episodio que ha sido recientemente reconstruido por parte de BEgUERÍA LATORRe, José Antonio y PERURENA Borobia, Ignacio: El conde de Fuentes. Vida, prisiones y muerte de Armando Pignatelli, Zaragoza, Institución «Fernando el Católico», 2009.

107 AGMS, leg. B-121 (Cesare Balbiani).

108 AGMS, leg. B-121 (Gaetano Balbiani). 
contrayendo matrimonio con María del Amparo Moto, heredera de un importante mercader genovés, Giovanni Moto, nacida en Gibraltar, donde la familia se había trasladado para controlar sus negocios con la Península ${ }^{109}$.

Como los Balbiani, otros italianos que se radicaron en España y dieron lugar a otras familias de fuerte tradición castrense recordaremos a los Baldoriotti, con Giuseppe Baldoriotti, originario de Florencia, teniente coronel; Filippo, su hijo nacido en Zaragoza; y Pietro, que se casó dos veces -en Cuernavaca con la hija de don Juan Flores Sanz, abogado de los reales consejos, y en Puerto Rico con una rica criolla Josefa Álvarez de Molina ${ }^{110}$. Los Beccaria que vieron Romeo Beccaria, hijo de militar originario de Lodi en el Ducado de Milán, que también supo conseguir un buen matrimonio con la hija primogénita y heredera de don Jacobo de Navia, regidor de la ciudad de Betanzos en el reino de Galicia, titular de un mayorazgo con una renta de 300 ducados anuales y 20.000 reales de bienes libres ${ }^{111}$.

Así pues, la persistencia de este fuerte núcleo de italianos al interno de las fuerzas armadas borbónicas respondía a un conjunto de factores. En primer lugar, la participación masiva de la aristocracia italiana en los planes de Felipe V servía para mantener viva la esperanza de recuperar los territorios perdidos al final de la guerra de Sucesión española. La obsesión italiana, que catalizó toda la política exterior de los primeros decenios del siglo, hasta por lo menos el 1746, cuando el fracaso militar de la expedición italiana y el hundimiento financiero del país hicieron que estos planes fueran definitivamente abandonado ${ }^{112}$, se mantenía también continuando a blasonar y premiar las elites del país vinculándolas a la nueva dinastía ${ }^{113}$. El apoyo de esta oficialidad fue determinante, desde el punto de vista de la Monarquía, para mantener, gracias a ellos, fuertes enlaces en el territorio gracias a las relaciones que siguieron conservando con las realidades de las que provenían, lo que en último término favoreció la persistencia de un fuerte sentimiento filo español. La presencia al mando del regimiento de infantería de Milán de un gran aristócrata lombardo como el conde Borromeo, por ejemplo, favoreció el ingreso en el regimiento de unos cuantos nobles vinculados a su familia ${ }^{114}$.

No solo, estos oficiales se demostraron fundamentales para conseguir los hombres que necesitaba el ejército. En varias ocasiones fueron ellos mismos quienes levantaron unidades enteras al servicio del rey, pagando de su proprio bolsillo, transformándose

\footnotetext{
109 AGMS, leg. B-122 (Raffaele Balbiani).

110 AGS, SG, leg. 2627, c. III, f. 5; AGMS, leg. B-248 (Filippo y Pietro Baldoriotti).

111 AGMS, leg. B-1311 (Romeo Beccaria).

112 Domínguez Ortiz, Antonio: Sociedad y Estado en el siglo XVIII español, Madrid, Ariel, 1976, pp. 73, 280281.

113 Una visión general de la diplomacia y política exterior de los primeros Borbones en las páginas de OzANAM, Didier: «La política exterior de España en tiempos de Felipe V y de Fernando VI. Los instrumentos de la política exterior. La diplomacia. La marina. El ejército», en Historia de España Ramón Menéndez Pidal, tomo XXIX, vol. I, La nueva Monarquía y su posición en Europa (1700-1759), Madrid, Espasa Calpe, 1985.

114 Como Francesco Gramegna de Pavía, que entró como cadete en la compañía coronela (AGS, SG, leg. 2618 c. I, f. 57); Baldassarre Pecorara, miembro de una importante familia de Pavía, que también ingresó en la compañía de Borromeo (AGS, SG, leg. 2818, c. I, f. 56); Ignazio Cermelli, también de Pavía, cadete en la guardia de corps con dicho conde y después capitán de caballería (AGS, SG, leg. 2479, c. I, f. 4); o, por último, el conde Benvenuti de Lodi, que empezó sus servicios en el dicho regimiento como teniente (AGS, SG, leg. 2618, c I, f. 6).
} 
en asentistas privados ${ }^{115}$, a cambio de un ascenso en el escalafón o del mando de las mismas compañías o regimientos, un sistema que, a imitación de Francia, se estaba institucionalizando todavía más en la España borbónica ${ }^{116}$. Así, territorios como la Republica de Génova, los Ducados de Parma y Piacenza (sobre todo después de los esponsales con Isabel Farnesio), los Estados de la Iglesia, con la ciudad de Roma a la cabeza, Toscana y, por supuesto, los dos reinos de Nápoles y de Sicilia, se transformaron en centros privilegiados de reclutamiento de estos asentistas que, como hemos visto, pertenecían a las grandes familias nobiliarias del país ${ }^{117}$. Recordaremos aquí, además de otros oficiales ya citados en las páginas anteriores, personajes como Carlo Fogliazzi, de la primera nobleza de Piacenza, que levantó unos cuantos hombres para la defensa de la dicha ciudad en 1744, hecho que le permitió ingresar como oficial en los reales ejércitos ${ }^{118}$; a Berengario Trigoria, que obtuvo los galones de sargento mayor gracias a la leva de una compañía de infantería ${ }^{119}$; o, por último, al conde Sebastiano Filangeri, ascendido a coronel por haber efectuado una leva a su $\operatorname{costa}^{120}$.

En segundo lugar, la persistencia de una vocación militar entre las élites italianas, casi totalmente desconocida por parte de la historiografía de este país, respondía a unas exigencias familiares que veían todavía en el servicio de las armas una providencial oportunidad para emplear a los segundones, aunque no sólo a ellos, al servicio de un príncipe extranjero ${ }^{121}$. Se trataba así de la posibilidad de conseguir nuevos lucimientos y honores para el blasón familiar y, sobre todo, de conservar con las oportunidades ofrecidas, gracias a las levas, su posición al interno de la oligarquía local.

115 Sobre la difusión de este sistema en la España del siglo XVIII remito a AndúJar CAStillo, Francisco: «La privatización del reclutamiento en el siglo XVIII: el sistema de asientos», Studia Historica. Historia Moderna, 25 (2003), pp. 123-147.

116 Andújar Castillo: op cit. (nota 69), passim. Sobre el modelo francés remito a las consideraciones de Drévillon, Hervé: L'impôt du sang. Le métier des armes sous Louis XIV, Paris, Tallandier, 2005; y RowLANDS, Guy: The Dynastic State and the Army under Louis XIV. Royal Service and Private Interest, 1661-1701, Cambridge, Cambridge University Press, 2002.

117 Andútar Castillo: op cit. (nota 13), pp. 127-128; Marchena Fernández: op cit. (nota 13), pp. 143-149.

118 AGS, SG, leg. 2626, c. XIII, f. 28.

119 AGS, SG, leg. 2636, c. X, f. 39.

120 AGS, SG, leg. 2618, c. II, f. 4.

121 Una visión de conjunto de las estrategias de la nobleza italiana se puede ver en DonAti, Claudio: «The Italian Nobilities in the Seventeenth and Eighteenth Centuries», en Scotт, H.M. (ed.): The European Nobilities in the Seventeenth and Eighteenth Centuries, vol. I, Western Europe, Londres, Longman, 1995, pp. 237-268. 